\title{
Audiology
}

\section{Influence of temporal resolution skills in speech discrimination abilities of older subjects}

\author{
Influenza della risoluzione temporale nelle abilità di discriminazione verbale \\ dei soggetti anziani
}

\author{
P.G. NAIR ${ }^{1}$, B.M. BASHEER ${ }^{2}$ \\ ${ }^{1}$ Department of Speech pathology and Audiology, Amrita Institute of Medical Sciences and Research Centre, \\ Amrita Vishwa Vidyapeetham University, Kochi, Kerala, India; ${ }^{2}$ Mar Thoma College of Special Education, Kerala \\ University of Health Sciences, Kasaragod, Kerala, India
}

\begin{abstract}
SUMMARY
Compromised temporal resolving power of the auditory system can be one of the main factors contributing to poor speech perception skills in the elderly. Very few of the earlier studies have systematically examined this aspect. Hence, the current study was designed with the following objectives: 1) To establish normative database of Gaps in Noise (GIN) test in elderly population in an Indian context. 2) To determine the relationship between speech discrimination skills and temporal resolution abilities in elderly individuals with normal hearing sensitivity. Thirty normal hearing elderly individuals (age range: $55-75$ years; mean age: $59.86 \pm 4.11$ years) participated in the study. The audiological evaluation comprised of tympanometry, puretone and speech audiometry (Speech Reception Threshold-SRT, Speech Discrimination Score-SDS) and GIN. The results of the present study revealed mean Gap Detection Threshold (GDT) of 8.7 msec (SD = $3.38)$ in the right ear and $8.83 \mathrm{msec}(\mathrm{SD}=2.86)$ in the left ear for the older participants. The mean Total Percentage Score (TPS) in the right ear was $47 \%(\mathrm{SD}=11.92)$ and $45 \%(\mathrm{SD}=11.29)$ in the left ear. These results suggest that temporal resolution abilities are poor in the elderly compared to the young and middle-aged group. There was no significant ear based difference on either GDT or TPS. The GDT was inversely correlated with speech discrimination performance. The TPS was positively correlated with SDS. This study clearly demonstrated a positive relationship between temporal resolution abilities and speech discrimination. The current database might be useful when assessing temporal resolution abilities in hearing impaired elderly individuals. Furthermore, all elderly individuals should undergo temporal resolution evaluation, irrespective of their hearing status, during audiological assessment.
\end{abstract}

KEY WORDS: Temporal resolution• Elderly group • Speech discrimination • GIN

\section{RIASSUNTO}

Un alterata capacità di risoluzione temporale del sistema uditivo può essere uno dei fattori alla base della ridotta discriminazione verbale nei soggetti anziani. Ben pochi studi in passato hanno approfondito questo aspetto in modo sistematico. Il presente studio si è pertanto posto come obiettivi: 1) Stabilire una normativa in una popolazione di anziani in un contesto culturale Indiano per il test Gaps in Noise (GIN); 2) Stabilire la relazione fra la discriminazione verbale e le capacità di risoluzione temporale in una popolazione di individui anziani normo udenti. Sono stati arruolati complessivamente trenta pazienti anziani normo udenti (età: 55-75 anni; età media: 59,86 \pm 4,11 anni). La valutazione audiologica si è composta di una timpanometria, audiometria tonale e vocale (Speech Reception Threshold-SRT, Speech Discrimination Score-SDS) e il GIN. I risultati del presente studio ci hanno permesso di determinare per la popolazione studiata un GDT (Gap Detection Threshold) medio di 8,7 millisecondi (SD : 3,38) per l'orecchio destro e di 8,83 millisecondi (SD : 2,86) per l'orecchio sinistro. Il TPS (Total Percentage Score) medio per l'orecchio destro è stato del 47\% (SD : 11,92) e per l'orecchio sinistro del $45 \%$ (SD : 11,29). I nostri risultati suggeriscono che le abilità di discriminazione temporale siano peggiori nei soggetti anziani rispetto ai soggetti giovani e adulti. Né il TPS né il GDT hanno mostrato differenze interaurali significative. Il GDT ha presentato una correlazione inversa con le performance di discriminazione verbale. Il TPS ha mostrato una correlazione diretta con l'SDS. Il presente studio dimostra in modo chiaro la relazione che intercorre fra la discriminazione verbale e le abilità di risoluzione temporale. Il presente database di dati rappresenta una risorsa per la valutazione delle abilità di risoluzione temporale in soggetti anziani affetti da ipoacusia. Riteniamo che tutti $i$ soggetti anziani vadano sottoposti a una valutazione delle abilità di risoluzione temporale nel corso di una valutazione dell'udito, indipendentemente dal fatto che siano o meno affetti da alterazioni uditive.

PAROLE CHIAVE: Risoluzione temporale $\bullet$ Anziani $\bullet$ Discriminazione verbale $\bullet$ GIN 


\section{Introduction}

Hearing loss (presbycusis) affects approximately one in three people between the ages of 65 and 74 years. By 75 years of age, nearly one-half of all individuals suffer from presbycusis ${ }^{1}$. Earlier, presbycusis was thought to be primarily a deficit in the function of the ear; however, recent studies revealed that there may be involvement of the central auditory system as well ${ }^{2}$.

Most elderly individuals, even without greater degree of hearing loss, have difficulty in understanding speech compared with younger adults in both noisy and quiet situations ${ }^{34}$. Elderly people also experience difficulty with all types of altered speech, i.e., fast speech ${ }^{56}$, interrupted speech ${ }^{57}$ and reverberated speech ${ }^{5}$. Smith and Prather ${ }^{8}$ found a decrement in performance for elderly listeners in comparison to young listeners for speech discrimination of consonant-vowel (CV) nonsense syllables across a range of sensation levels (SLs) and signal-to-noise (S/N) ratios.

Temporal cues in auditory signals are the basis for speech discrimination ${ }^{9}$ especially for detecting rise/fall time ${ }^{10}$, voice onset time (VOT) ${ }^{11-14}$ and other transient part of the stimuli (onset of syllables). Accurate speech discrimination requires precise temporal processing ${ }^{15}$. According to Shinn ${ }^{16}$, temporal processing may be conceptualised as four sub-processes which include temporal resolution, temporal patterning, temporal integration and temporal masking. These skills are particularly crucial for phonemic distinction, lexical and prosodic distinctions and auditory closure ${ }^{17}$.

Reduced temporal resolving power of the auditory system can be one of the main factors contributing to poor speech perception skills in elderly. It is reported that temporal resolution skills decline before the age of 60 years even in individuals with normal hearing sensitivity ${ }^{18} 19$.

As per the technical report by the American SpeechLanguage-Hearing Association ${ }^{20}$, temporal resolution is considered as an important component of central auditory processing. Gap detection (GD) is one of the most common measures to assess temporal resolution. Numerous studies have reported elevated GD thresholds in elderly individuals with hearing loss ${ }^{21-23}$. A few studies have also reported elevated GD thresholds in elderly individuals with normal hearing sensitivity ${ }^{24} 25$.

Very few of the earlier studies have systematically examined changes in auditory temporal resolution and speech perception performance in elderly individuals with normal hearing sensitivity. Hence, the current study was designed to focus on the influence of temporal resolution skills (measured by GD) on speech discrimination abilities in elderly individuals with normal hearing sensitivity (as investigated by puretone audiometry). GD measures were obtained using Gaps-In-Noise (GIN) test. The present study had two objectives: 1) To estab- lish normative database of GIN test in the elderly population in an Indian context, 2) To determine the relationship between speech discrimination skills and temporal resolution abilities in elderly individuals with normal hearing sensitivity.

\section{Materials and methods}

Thirty normal hearing (puretone thresholds of $\leq 25 \mathrm{~dB}$ hearing level-HL from $0.25 \mathrm{kHz}$ to $8.0 \mathrm{kHz}$ ) elderly individuals (age range: $55-75$ years; mean age: $59.86 \pm 4.11$ years) participated in the study. All had normal middle ear function as shown by 'A' type tympanogram. None had history of noise exposure, ear infections, or any other neurological/psychiatric conditions. Informed consent was obtained from all participants.

The audiological evaluation comprised of tympanometry, puretone and speech audiometry (Speech Reception Threshold-SRT, Speech Discrimination Score-SDS) and GIN. For obtaining SRT, the presentation level was set at intensity $20 \mathrm{~dB}$ higher than the puretone average. The subject was presented with spondee words one at a time. The lowest intensity level at which 50\% of correct responses were obtained was considered as the SRT. For obtaining SDS, the presentation level was set at intensity $40 \mathrm{~dB}$ higher than the SRT. The subject was presented with 20 phonetically balanced monosyllables. Each correct repetition of the syllable carried 5\% and the SDS was calculated using the formula:

$\mathrm{SDS}=\underline{\text { Number of correct responses }} \times 100$.

Total number of stimuli

The GIN test was presented through dual channel audiometer (GSI 61 clinical-diagnostic audiometer with TDH-50 $\mathrm{P}$ earphones). The test $\mathrm{CD}$ was played using a $\mathrm{CD}$ player connected to the audiometer. The GIN test was administered bilaterally and scoring was done as per the standard criteria ${ }^{26}$. The stimulus was presented at 35-50 decibel Sensation Level (dB SL) with reference to puretone average. The indices used were Gap Detection Threshold (GDT) and Total Percentage Score (TPS). Practice list provided in the test was used to train the participants for comprehension of the task. The test was comprised of four different lists containing up to 36 signal segments of 6 seconds white noise in each list. The number of gaps of silence in each signal varied from 0-3. The duration of each gap were either $2,3,4,5,6,8,10,12,15$ or $20 \mathrm{msec}$ with each silence gap duration occurring six times in each GIN list. Thus, each GIN list consisted of a total of 60 gaps and the order of gap durations were randomised. A five sec gap of silence separated each six sec noise segment. One list was administered in each ear. While administering the test, subjects were instructed to listen for any silence gap that may or may not occur within each noise burst. As soon as the gap was detected, the subject had to respond by pressing a button. 
The GDT was calculated by considering: (1) minimum gap duration correctly identified 4 out of 6 times and (2) similar or better performance for longer gap durations. The TPS was calculated by dividing the total number of gap durations correctly identified by the total number of gap durations presented $(n=60)$ multiplied by 100. False positives were noted separately. More than two false positives per ear were counted as errors and subtracted from the number of gap durations correctly identified.

The entire test procedure was carried out in a sound-treated room. The ambient noise levels were maintained within the permissible levels according to American National Standards Institute ${ }^{27}$.

\section{Results}

\section{Demographic data}

Among participants, there were 20 males (66\%) and 10 (34\%) females. All participants presented with normal hearing sensitivity whose mean and standard deviation (SD) of Puretone Average (PTA) (average of air conduction-AC thresholds at $500 \mathrm{~Hz}, 1 \mathrm{kHz}$ and $2 \mathrm{kHz}$ ) and All Frequency Average -AFA (average of AC thresholds at $250 \mathrm{~Hz}, 500 \mathrm{~Hz}, 1 \mathrm{kHz}, 2 \mathrm{kHz}, 4 \mathrm{kHz}, 6 \mathrm{kHz} \& 8 \mathrm{kHz})$ of each ear were computed separately (Table I).

\section{Speech Discrimination Score (SDS)}

Descriptive statistical analysis was done and calculated the mean $(M)$ and standard deviation $(S D)$ for SDS in the right ear $(M=91.83 \%, S D=8.54)$ and in the left ear $(M=90.33 \%$, $S D=8.89$ ) for all participants. A parametric, two-tailed paired $t$ test was used to analyse the ear- based performance difference on SDS. The results revealed that there was no significant difference between the performance of the right and left ears on SDS $(t(29)=1.964, p=0.059)$.

\section{Performance on Gaps-In- Noise (GIN) test}

The two measures derived were GDT and TPS. Mean and standard deviation for both measures were obtained. The ear based performance was analysed for both measures using two-tailed paired $t$ test. There was no significant ear based difference on either GDT (Table II) or TPS (Table III). Both ears performed equally for the GIN test.

The other objective of the current study was to determine whether there is any relationship between performance on the GIN test and speech discrimination. To address this issue, the Pearson $r$ correlation analysis was computed using the following variables: GDT, TPS and SDS (Table IV).

The correlation analysis revealed two significant correlations of interest. The GDT was inversely correlated with speech discrimination performance as shown below: For GDT right and SDS right $(r=-0.566, p<0.05)$ and for
Table I. Mean (M) and standard deviation (SD) of PTA and AFA in the elderly population.

\begin{tabular}{lll}
$\mathrm{n}=\mathbf{3 0}$ & MEAN $(\mathrm{M})$ & $\mathrm{SD}$ \\
PTA RT $(\mathrm{dB})$ & 17.60 & 3.75 \\
PTA LT $(\mathrm{dB})$ & 19.06 & 6.69 \\
AFA RT $(\mathrm{dB})$ & 20.40 & 4.48 \\
AFA LT $(\mathrm{dB})$ & 21.42 & 5.65 \\
\hline PTA
\end{tabular}

PTA, pure tone average; AFA, all frequency average; $R T$ for right ear and LT for left ear

Table II. Results of t-test and descriptive statistics for Gap Detection Threshold (GDT) in the right and left ears.

\begin{tabular}{|c|c|c|c|c|c|}
\hline & $\begin{array}{l}\text { Right ear } \\
(n=30)\end{array}$ & $\begin{array}{l}\text { Left ear } \\
(n=30)\end{array}$ & $t \quad t$ & Df & $\begin{array}{l}95 \% \mathrm{Cl} \text { of the } \\
\text { difference }\end{array}$ \\
\hline & Mean (SD) & Mean (SD) & & & \\
\hline $\begin{array}{l}\text { GDT } \\
\text { (msec) }\end{array}$ & $8.7(3.28)$ & $8.83(2.86)$ & -0.394 & 29 & $-0.824,0.558$ \\
\hline
\end{tabular}

Table III. Results of t-test and descriptive statistics for Total Percentage Score (TPS) in the right and left ears.

\begin{tabular}{|c|c|c|c|c|c|}
\hline & $\begin{array}{l}\text { Right ear } \\
(n=30)\end{array}$ & $\begin{array}{l}\text { Left ear } \\
(n=30)\end{array}$ & $t \quad t$ & Df & $\begin{array}{l}95 \% \mathrm{Cl} \text { of the } \\
\text { difference }\end{array}$ \\
\hline & Mean (SD) & Mean (SD) & & & \\
\hline TPS & 47.96 (11.92) & $\begin{array}{l}45.03 \\
(11.29)\end{array}$ & 0.769 & 29 & $-1.771,3.920$ \\
\hline
\end{tabular}

GDT left and SDS left $(\mathrm{r}=-0.644, p<0.05)$. These results indicated that as the GDT improved, speech discrimination abilities were better.

The TPS was positively correlated with SDS. It should be noted that the correlation between these variables was assessed for both ears (i.e., for TPS and SDS in right ear, $r=0.389, p<0.05$ and for TPS and SDS in left ear, $r=0.506, p<0.05)$.

\section{Discussion}

Temporal resolution is, most likely, one of the basic components for speech perception and its assessment may provide information about the neural integrity of the central auditory nervous system ${ }^{2}$. The results of the present study documented a mean GDT of $8.7 \mathrm{msec}(\mathrm{SD}=3.38$ ) in the right ear and $8.83 \mathrm{msec}(\mathrm{SD}=2.86)$ in the left ear for the older participants. The mean TPS in the right ear was $47 \%(\mathrm{SD}=11.92)$ and $45 \%(\mathrm{SD}=11.29)$ in the left ear. These findings are different from those observed for the adult population previously. Museik et al. ${ }^{26}$ found relatively lower mean GDT (right ear $=4.9 \mathrm{msec}$ and left ear $=4.8 \mathrm{msec})$ and comparatively higher TPS score $(70 \%$ bilaterally) for the adult population of the age range of 13 to 46 years. When the GIN test was employed in an Indian 
Table IV. Result of Pearson $r$ Correlation among three variables of the elderly participants.

\begin{tabular}{|c|c|c|c|c|c|c|c|}
\hline & & SDS (RT) & SDS(LT) & GDT( RT) & GDT LT & TPS (RT) & TPS (LT) \\
\hline \multirow[t]{3}{*}{ SDS (RT) } & Pearson Correlation & 1 & $0.88^{\star \star}$ & $-0.566^{\star \star}$ & $-0.445^{\star}$ & $0.389^{\star}$ & $0.459^{\star}$ \\
\hline & Sig. (2-tailed) & & 0.000 & & 0.014 & 0.034 & 0.011 \\
\hline & $\mathrm{N}$ & 30 & 30 & 30 & 30 & 30 & 30 \\
\hline \multirow[t]{3}{*}{ SDS (LT) } & Pearson Correlation & $0.885^{\star \star}$ & 1 & $-0.599^{\star \star}$ & $-0.644^{\star *}$ & $0.493^{\star \star}$ & $0.506^{\star *}$ \\
\hline & Sig. (2-tailed) & 0.000 & & 0.000 & 0.001 & 0.006 & 0.004 \\
\hline & $\mathrm{N}$ & 30 & 30 & 30 & 30 & 30 & 30 \\
\hline \multirow[t]{3}{*}{ GDT (RT) } & Pearson Correlation & $-0.566^{\star \star}$ & $-0.599^{\star \star}$ & 1 & $0.827^{\star \star}$ & $-0.846^{\star \star}$ & $-0.742^{\star \star}$ \\
\hline & Sig. (2-tailed) & 0.001 & 0.000 & & 0.000 & 0.000 & 0.000 \\
\hline & $\mathrm{N}$ & 30 & 30 & 30 & 30 & 30 & 30 \\
\hline \multirow[t]{3}{*}{ GDT (LT) } & Pearson Correlation & $-0.445^{*}$ & $-.0644^{\star \star}$ & $0.827^{\star \star}$ & 1 & $-0.740^{\star \star}$ & $-0.698^{* \star}$ \\
\hline & Sig. (2-tailed) & 0.014 & 0.000 & 0.000 & & 0.000 & 0.000 \\
\hline & $\mathrm{N}$ & 30 & 30 & 30 & 30 & 30 & 30 \\
\hline \multirow[t]{3}{*}{ TPS (RT) } & Pearson Correlation & $0.389^{\star}$ & $0.493^{\star \star}$ & $-0.846^{\star \star}$ & $-0.740^{\star *}$ & 1 & $0.787^{\star *}$ \\
\hline & Sig. (2-tailed) & 0.034 & 0.006 & 0.000 & 0.000 & & 0.000 \\
\hline & $\mathrm{N}$ & 30 & 30 & 30 & 30 & 30 & 30 \\
\hline \multirow[t]{3}{*}{ TPS (LT) } & Pearson Correlation & $0.459^{*}$ & $0.506^{\star \star}$ & $-0.742^{\star \star}$ & $-0.698^{\star \star}$ & $0.787^{\star \star}$ & 1 \\
\hline & Sig. (2-tailed) & 0.011 & 0.004 & 0.000 & 0.000 & 0.000 & \\
\hline & $\mathrm{N}$ & 30 & 30 & 30 & 30 & 30 & 30 \\
\hline
\end{tabular}

${ }^{* *}$ Correlation is significant at the 0.01 level (2-tailed).

* Correlation is significant at the 0.05 level (2-tailed).

context for the normative data (age range $=17-60$ years), the mean GDT obtained was $5.82 \mathrm{msec}$ in the right ear and 5.84 in the left ear. Mean TPS in the right ear was $62.99 \%$ and $63.25 \%$ in the left ear ${ }^{28}$. However, results similar to the present findings were observed in a study on older women $(\mathrm{n}=33$, age range $=$ early $60 \mathrm{~s})$ with overall average GDT of $8.3 \mathrm{msec}$. TPS was not considered in that study ${ }^{29}$. Hence, it is clear that older individuals demonstrate poor temporal resolution skills in comparison to younger and middle-aged individuals. The study done by Snell $\&$ Frisina ${ }^{30}$ also supported this finding. These results suggest that age-related changes in the central auditory system can contribute to deterioration of temporal resolution abilities in the elderly group in spite of normal hearing sensitivity.

The performance between ears of older individuals did not show any significant difference for either GDT or TPS. This suggests equal performance of both ears on the GIN test. Similar findings were observed by Shinn, Chermak \& Musiek ${ }^{31}$ in a very young population $(\mathrm{n}=72)$ and in an adult population ${ }^{28}$.

To establish the relationship between temporal resolution skills and speech discrimination abilities in elderly individuals, a correlation analysis was done. Speech discrimination abilities demonstrated positive correlation with TPS and negative correlation with GDT. Similar findings in middle-aged women were reported by Helfer \& Vargo ${ }^{19}$, using the GIN test and considering speech understanding ability in competing speech situations.

From the present study, we obtained a normative database of the GIN test for the elderly population. This may be useful when assessing temporal resolution abilities in hearing impaired elderly individuals.
It should also be noted that the proportion of elderly individuals have tremendously increased in modern society because of advancements in medical care. Hence, the current study has great social relevance. The subtle mechanisms involved in speech understanding difficulty in elders needs to be clearly understood. Such information may be crucial in planning rehabilitation strategies. This study also has relevance in the Indian context as the relationship between temporal resolution and speech understanding has not been thoroughly investigated.

The present study could have considered a larger database of elderly population for better validation. Furthermore, gender-based differences in terms of temporal resolution in elderly were not assessed. These aspects can be considered as the limitations of the study.

The elderly should be counseled to take effective steps to avoid further deterioration in auditory function by getting exposed to noisy environments, overuse of mobile phones or persisting with harmful habits like smoking. Additionally, in our opinion all elderly individuals should undergo temporal resolution evaluation irrespective of their hearing status during audiological assessment.

\section{Conclusions}

The present study clearly indicated that temporal resolution skills are impaired even in normal hearing elderly individuals. The observed decline in temporal and speech processing abilities in normal hearing older population might be due to compromised function of central auditory system. Furthermore, the normative database that was obtained for GIN test in elderly population can be useful 
in clinical assessment of hearing impaired elderly individuals. Future research should focus on comparing temporal resolution skills in the normal hearing elderly group with age-matched subjects with varying types of pathologies (conductive, sensory and neural) to understand the effects of each on temporal resolution.

\section{References}

1 National Institute on Deafness and Other Communication Disorders. Hearing loss and older adults. NIH Publication No 2014;01-4913.

2 Gordon-Salant S, Fitzgibbons PJ. Temporal factors and speech recognition performance in young and elderly listeners. J Speech Lang Hear Res 1993;36:1276-85.

3 Helfer KS,Wilber LA. Hearing loss, age and speech perception in reverberation and noise. J Speech Lang Hear Res 1990;33:149-55.

4 Wingfield A, McCoy SL, Peelle JE, et al. Effects of adult aging and hearing loss on comprehension of rapid speech varying in syntactic complexity. J Am Acad Audiol 2006;17:487-97.

5 Bergman M, Blumenfeld WG, Cascardo D, et al. Age-related decrement in hearing for speech. J Gerontol 1976;31:533-8.

6 Calearo C, Lazzaroni A. Speech intelligibility in relation to the speed of the message. Laryngoscope 1957;67:410-9.

7 Kirikae I, Sato T, Oshima H, et al. A study of hearing test using interrupted speech. Nihon Jibiinkoka Gakkai Kaiho 1964;67:245-54.

8 Smith RA, Prather WF. Phoneme discrimination in older persons under varying signal-to-noise conditions. J Speech Lang Hear Res 1971;14:630-8.

9 Amaral MIRD, Colella-Santos MF. Temporal resolution: performance of school-aged children in the GIN-Gaps-innoise test. Braz J Otorhinolaryngol 2010;76:6:745-52.

10 Delgutte B, Kiang NY. Speech coding in the auditory nerve: IV. Sounds with consonant like dynamic characteristics. J Acoust Soc Am 1984;75:897-907.

11 Sinex DG, McDonald LP. Average discharge rate representation of voice onset time in the chinchilla auditory nerve. J Acoust Soc Am 1988;83:1817-27.

12 Sinex DG, McDonald LP, Mott JB. Neural correlates of nonmonotonic temporal acuity for voice onset time. J Acoust Soc Am 1991;90:2441-9.

13 Sinex DG. Auditory nerve fibre representation of cues to voicing in syllable-final stop consonants. J Acoust Soc Am 1993;94:1351-62.

14 Sinex DG, Narayan SS. Auditory nerve fibre representation of temporal cues to voicing in wordmedial stop consonants. J Acoust Soc Am 1994;95:897-903.
15 Anderson S, Parbery-Clark A, White-Schwoch T, et al. Aging affects neural precision of speech encoding. $\mathrm{J}$ Neurosc 2012;32:14156-64.

16 Shinn J. Temporal processing and temporal patterning tests. In: Musiek F, Chermak G (Eds.). Handbook of (Central) Auditory Processing Disorders: Auditory Neuroscience and Diagnosis. San Diego: Plural Publishing 2007.

17 Chermak G, Musiek F. Central auditory processing disorders: new perspectives. San Diego: Singular 1997.

18 Grose JH, Hall III JW, Buss E. Temporal processing deficits in the pre-senescent auditory system. J Acoust Soc Am 2006;119:2305-15.

19 Helfer KS, Vargo M. Speech recognition and temporal processing in middle-age women. J Am Acad Audiol 2009; 20:246-71.

20 American Speech-Language-Hearing Association. (Central) Auditory processing disorders 2005. Available at http://www. asha.org/members/deskref-journals/deskref/default.

21 Fitzgibbons PJ, Wightman FL. Gap detection in normal and hearing-impaired listeners. J Acoust Soc Am 1982;72:761-5.

22 Glasberg BR, Moore BC, Bacon SP. Gap detection and masking in hearing-impaired and normal-hearing subjects. J Acoust Soc Am 1987;81:1546-56.

23 Irwin RJ, Hinchcliff LK, Kemp S. Temporal acuity in normal and hearing impaired listeners. Audiology 1981;20:234-43.

24 Schneider BA, Hamstra SJ. Gap detection thresholds as a function of tonal duration for younger and older listeners. $\mathbf{J}$ Acoust Soc Am 1999;106:371-80.

25 Schneider BA, Pichora-Fuller MK, Kowalchuk D. Gap detection and the precedence effect in young and old adults. $\mathrm{J}$ Acoust Soc Am 1994;95:980-91.

26 Musiek F, Shinn J, Jirsa B, et al. GIN (Gaps-In-Noise) test performance in subjects with confirmed central auditory nervous system involvement. Ear Hear 2005;26:608-18.

27 American National Standards Institute (ANSI). Methods for the calculation of the Articulation Index. New York: American National Standards Institute 1969.

28 Prem G, Shankar NS, Girish N. Gaps In Noise (GIN) TestNormative Data. Amrita J Med 2012;8:24-8.

29 Yazaki M, Matsuhira T. Auditory temporal resolution and word recognition in noise in older women. $\mathrm{J}$ Kitasato Med 2014;44:17-25.

30 Snell KB, Frisina DR. Relationships among age-related differences in gap detection and word recognition. J Acoust Soc Am 2000;107:1615-26.

31 Shinn JB, Chermak GD, Musiek FE. GIN (Gap-In-Noise) Performance in the pediatric population. J Am Acad Audiol 2009;20:229-38. 